\title{
Evaluating biological significance of chemical exposure to fish using a bioenergetics-based stressor-response model ${ }^{1}$
}

\author{
Daniel W. Beyers, James A. Rice, and William H. Clements
}

\begin{abstract}
We demonstrate how contaminant exposure-response relationships can be integrated with a bioenergetics model to estimate the biological significance of sublethal exposure under fluctuating environmental conditions. The integrated bioenergetics-based stressor-response model (SRM) was evaluated by comparing observed and predicted growth of largemouth bass (Micropterus salmoides) exposed to several dieldrin concentrations and by conducting sensitivity analyses. Predictions of the SRM suggest that energetic effects of exposure of largemouth bass to ambient concentrations of dieldrin in lakes at the Rocky Mountain Arsenal National Wildlife Refuge are not biologically significant because the amount of energy lost by resident fish is small compared with variation in food consumption. Furthermore, influence of dieldrin exposure is small compared with the effects of a natural stressor like water temperature. The SRM provides a general framework for integrating laboratory-derived exposure-response relationships with ecological processes to determine the biological significance of multiple stressors in a natural environment. Comparisons of relative effects of anthropogenic and natural stressors can be used to assess potential costs and benefits of alternative ecosystem management strategies.
\end{abstract}

\begin{abstract}
Résumé : Les auteurs démontrent comment l'intégration dans un modèle bioénergétique des relations entre l'exposition à un contaminant et les réactions qui s'ensuivent permet d'estimer le retentissement biologique d'une exposition sublétale en présence de conditions environnementales variables. Ils ont évalué ce modèle bioénergétique intégré en comparant les taux de croissance observés et théoriques d'achigans à grande bouche (Micropterus salmoides) exposés à plusieurs concentrations de dieldrine et en effectuant des analyses de sensibilité. Les valeurs prédites par le modèle donnent à croire que, chez l'achigan à grande bouche, les effets énergétiques d'une exposition à des concentrations ambiantes de dieldrine dans les lacs du Rocky Mountain Arsenal National Wildlife Refuge n'ont pas un retentissement biologique important parce que la perte d'énergie subie par les poissons est faible en comparaison des fluctuations de consommation de nourriture. En outre, l'effet de l'exposition à la dieldrine est faible en comparaison de l'incidence de certains facteurs de stress naturels comme la température de l'eau. Le cadre général fourni par le modèle permet d'intégrer les relations déduites en laboratoire entre l'exposition à un contaminant et les réactions qui s'ensuivent à un processus écologique en vue de déterminer le retentissement biologique de facteurs de stress multiples dans un environnement naturel. Par comparaison de l'incidence relative de facteurs de stress anthropiques et naturels, il devient possible d'évaluer les coûts et les avantages éventuels de nouvelles stratégies de gestion des écosystèmes.
\end{abstract}

[Traduit par la Rédaction]

\section{Introduction}

Mechanistic computer models have been used to summarize the energy budgeting process, food consumption, and growth of a variety of fish and fish populations (Kitchell

Received April 6, 1998. Accepted December 9, 1998.

$\mathrm{J} 14542$

D.W. Beyers. ${ }^{2}$ Larval Fish Laboratory, Department of Fishery and Wildlife Biology, Colorado State University, Fort Collins, CO 80523, U.S.A.

J.A. Rice. Department of Zoology, North Carolina University, Raleigh, NC 27695-7617, U.S.A.

W.H. Clements. Department of Fishery and Wildlife Biology, Colorado State University, Fort Collins, CO 80523, U.S.A.

${ }^{1}$ Contribution 105, Larval Fish Laboratory, Department of Fishery and Wildlife Biology, Colorado State University, Fort Collins, CO 80532, U.S.A.

${ }^{2}$ Author to whom correspondence should be addressed.

e-mail: danb@lamar.colostate.edu
1983; Adams and Breck 1990; Rice 1990; Brandt and Hartman 1993; Hanson et al. 1997). These models use an energetics-based approach that accounts for physiological mechanisms and environmental conditions that regulate growth of individual fish. In traditional applications of these models, environmental conditions like water temperature and prey density are regarded as external factors (driving variables) that regulate food consumption and growth. Alternatively, these external variables can be considered as natural sources of physiological stress to fish. In a companion paper, Beyers et al. (1999) described the conceptual basis for integrating energetics and stress and defined stress as "...the change in the energy budget resulting from the combined effects of specific and nonspecific responses to a stressor." Within this framework, existing bioenergetics models can quantify effects of natural stressors and can account for the influence of individual characteristics on the basic energetics budget of fish (Fig. 1).

Natural environmental factors are not the only influences that can be included in a bioenergetics model. Effects of 
Fig. 1. Conceptual representation of how effects of natural and anthropogenic stressors are integrated using a bioenergetics-based SRM. The basic bioenergetics model accounts for individual characteristics of fish and adjusts their energy budget in response to changing environmental stressors. The SRM integrates these effects with those from anthropogenic sources according to stressor magnitude and duration. The integrated model reallocates energy expenditures so that costs of maintenance are met and resulting effects are manifested as changes in growth or reproduction.

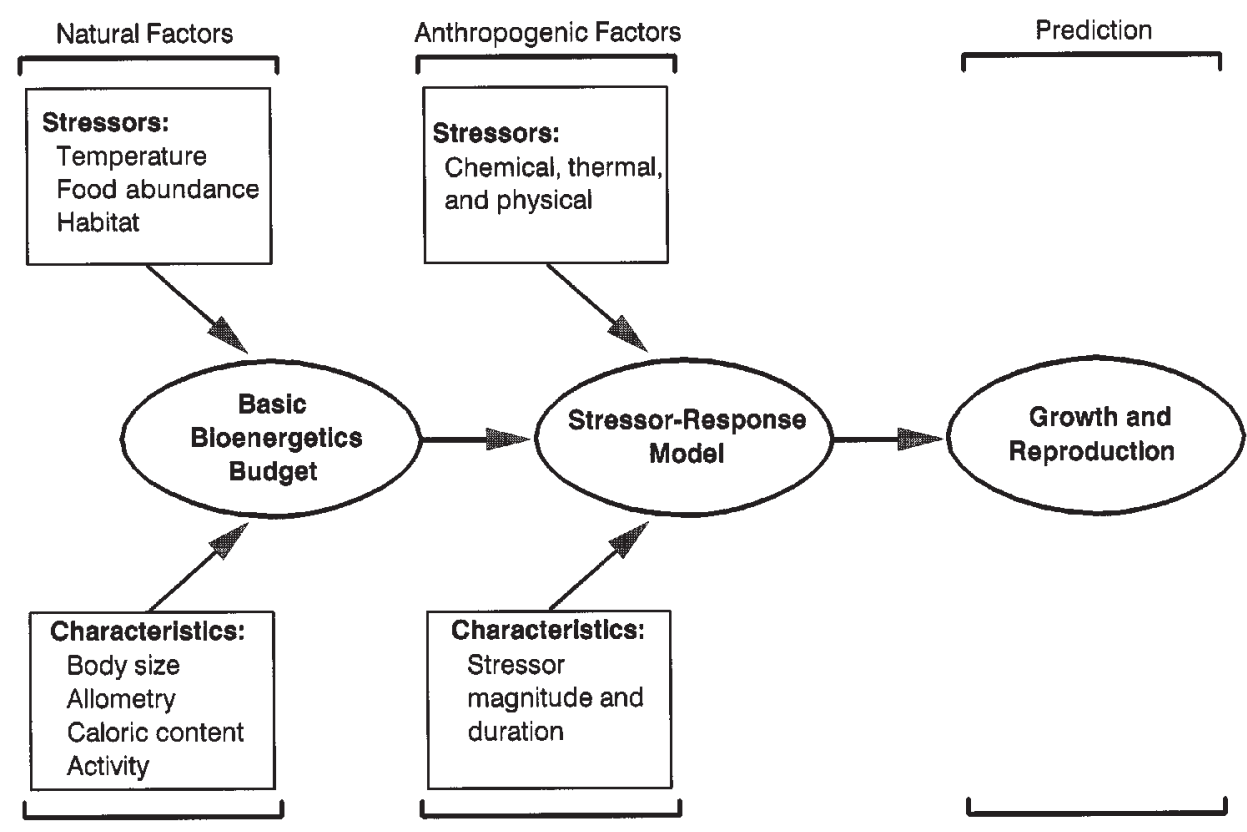

anthropogenic stressors can also be included in the model by integrating stressor-response relationships (Rice 1990; Beyers and Sikoski 1994). Beyers et al. (1999) showed how the energetic cost of a chemical stressor (dieldrin) can be quantified in terms of exposure-response relationships for oxygen and food consumption of juvenile largemouth bass (Micropterus salmoides). In this paper, we demonstrate how these relationships can be combined with the basic fish bioenergetics budget to produce a bioenergetics-based stressorresponse model (SRM) that is useful for evaluating effects of multiple stressors on fish (Fig. 1). Accuracy of the model was evaluated by comparing observed and predicted growth of largemouth bass exposed to several dieldrin concentrations. Model performance was further evaluated by conducting Monte Carlo sensitivity analyses. Results of the SRM are intended to assist risk managers in assessment of costs and benefits of remediating chemical contaminants in the sediment and water of several lakes at the Rocky Mountain Arsenal National Wildlife Refuge (Commerce City, Colorado). The model was used to predict the effect of exposure of largemouth bass to ambient concentrations of dieldrin and to quantify potential benefits of alternative ecosystem management strategies.

The proposed approach has several advantages over traditional methods for assessing effects of contaminant exposure. First, it permits comparison of the relative effects of stressors so that they can be ranked according to the magnitude of their influence on the bioenergetics budget of a fish. Second, the effects of human-induced stress can be compared with those of natural environmental stressors. These comparisons provide a basis for risk managers to estimate when an anthropogenic stressor has been reduced to a level that is no longer biologically significant relative to natural environmental factors. Third, and perhaps most important, a bioenergetics approach provides a mechanism for extending laboratory-derived exposure-response relationships to realworld situations where natural environmental conditions change over time. Traditional toxicity tests are conducted in the laboratory where natural environmental variability is eliminated; consequently, these tests are very useful for demonstrating cause-effect relationships but lack ecological realism. Because bioenergetics models simulate the influence of a fluctuating environment on fish physiology, they can integrate effects of natural variability and chemical exposure, thereby increasing our ability to predict consequences of exposure in the field.

\section{Methods}

\section{Field data}

Dieldrin concentrations in Lower Derby Lake at the Refuge were quantified by collecting a total of 31 water samples on 13 occasions (12 June to 11 November 1996). Three spiked samples were also prepared and submitted for analysis on one occasion. Measured concentrations were adjusted for recovery of dieldrin from spiked samples $(61.1 \%, \mathrm{SE}=14.5)$. The mean dieldrin concentration of all lake samples was estimated with Helsel's robust method for analysis of trace-level water quality data (Helsel 1990) using the computer program UnCensor ${ }^{\complement}$ (Newman et al. 1995). The estimated mean measured dieldrin concentration in Lower Derby Lake was $7.73 \mathrm{ng} \cdot \mathrm{L}^{-1}(\mathrm{SE}=0.729)$.

\section{Model development}

\section{Basic bioenergetics model}

Bioenergetics models for fish derive from the same general equation (Warren 1971; Brett and Groves 1979; Kitchell 1983). The equation represents an energy budget that balances energy intake from prey consumption against expenditures for metabolism, 
waste production, and storage of surplus energy in the form of growth. The model has the form

$$
C=R+A+S+F+U+\Delta B
$$

where $C$ is food consumption, $R$ is metabolism, $A$ is activity, $S$ is specific dynamic action (the cost of processing food), $F$ is egestion (feces), $U$ is excretion (urine), and $\Delta B$ is somatic growth and reproductive growth in mature individuals. For purposes of simulation modeling, the general equation has been reformulated to describe growth as an integration of rate-specific physiological processes. We used the formulation for largemouth bass based on Rice et al. (1983) as modified by Hewett and Johnson (1992):

$$
\frac{\mathrm{d} B}{B \cdot \mathrm{d} t}=C-(R+S+F+U) \text {. }
$$

Food consumption is estimated as $C=C_{\max } \cdot p \cdot f(T)$, where $C$ is the daily ration (g prey.g bass ${ }^{-1} \cdot \mathrm{day}^{-1}$ ) for a fish at a particular mass and temperature, $C_{\max }$ is a mass-dependent function for maximum specific feeding rate $\left(\mathrm{g}\right.$ prey.g bass $\left.{ }^{-1} \cdot \mathrm{day}^{-1}\right), p$ is the realized proportion of maximum consumption (unitless), and $f(T)$ is the temperature dependence function for maximum food consumption (unitless). Respiration is estimated as $R=0.00279 \cdot W^{-0.355}$. $f(T) \cdot \mathrm{OC} \cdot \mathrm{ED}^{-1} \cdot \mathrm{ACT}$, where $R$ is the amount of energy used for routine metabolism (g bass.g bass ${ }^{-1} \cdot \mathrm{day}^{-1}$ ) for a fish at a particular mass, temperature, and activity level, $W$ is fish mass ( $\mathrm{g}), f(T)$ is the temperature dependence function for respiration (unitless), OC is an oxycalorific coefficient of $13556 \mathrm{~J} \cdot \mathrm{g} \mathrm{O}_{2}{ }^{-1}$ (Elliot and Davidson 1975), ED is the assumed largemouth bass wet mass energy density of $4184 \mathrm{~J} \cdot \mathrm{g}^{-1}$, and ACT is an activity multiplier (unitless). Specific dynamic action, egestion, and excretion are estimated as constant proportions of food consumption (see Hewett and Johnson 1992). Energy densities of largemouth bass and their prey were assumed to be constant and equivalent. Preliminary analyses with this form of the basic bioenergetics model showed that its estimates of fish growth and expenditures for metabolism and waste production were identical to those of Hewett and Johnson (1992).

\section{Stressor effects}

Beyers et al. (1999) studied the effects of dieldrin exposure on juvenile largemouth bass and presented regression equations that described the response of food consumption, metabolic rate, and growth as functions of exposure concentration and duration. Two of these equations were incorporated into the basic bioenergetics model. The first equation described the effect of dieldrin exposure on specific food consumption $\left(\mathrm{g}\right.$ prey.g $\left.\mathrm{bass}^{-1} \cdot \mathrm{day}^{-1}\right)$ :

$$
\begin{aligned}
\log _{10}(\text { specific consumption })=-1.69- & 1.70 \times 10^{-4}(\mathrm{DC}) \\
+ & 1.81 \times 10^{-8}\left(\mathrm{DC}^{2}\right)
\end{aligned}
$$

where DC is dieldrin concentration $\left(\mathrm{ng} \cdot \mathrm{L}^{-1}\right)$. This concentrationresponse relationship was estimated from fish that were exposed to five dieldrin concentrations (control, 963, 1840, 3140, and $5790 \mathrm{ng} \cdot \mathrm{L}^{-1}$ ) for 16 days while being offered a daily ration of live fathead minnows (Pimephales promelas) at a rate of about $2 \%$ of their body mass per day.

The second equation described the change in metabolic rate of largemouth bass $\left(\mathrm{g} \mathrm{O}_{2} \cdot \mathrm{g} \mathrm{bass}^{-1} \cdot\right.$ day $\left.^{-1}\right)$ that resulted from chemical exposure:

$$
\begin{aligned}
\Delta \text { metabolism } & =3.91 \times 10^{-6}-4.19 \times 10^{-7}(\mathrm{DC}) \\
+ & 5.41 \times 10^{-11}\left(\mathrm{DC}^{2}\right)+1.76 \times 10^{-8}(\mathrm{DC} \cdot \mathrm{DE})
\end{aligned}
$$

where DE is duration of exposure (days). This relationship was estimated from fish that were exposed to the same five dieldrin concentrations for five durations $(1,2,4,8$, and 16 days). Thus, the regression equation predicts the change in metabolic rate at any time during the first 16 days of exposure relative to control fish. In applications of the SRM that required estimates of $\Delta$ metabolism for longer durations of exposure, the 16-day value was used as a substitute. Justification for this substitution is based on predictions of a conceptual model called the general adaptation syndrome that describes how physiological systems respond to stressors (Selye 1956, 1973; Beyers et al. 1999). Based on this concept, we assumed that long durations of exposure result in an increase of $\Delta$ metabolism to a limit approximated by metabolic rates of fish in the 16-day exposure.

\section{SRM}

Stressor effects were integrated into the basic bioenergetics model in the form of proportions that adjusted food consumption and metabolism to account for chemical exposure. The SRM had the form

$$
\frac{\mathrm{d} B}{B \cdot \mathrm{d} t}=C \cdot \Delta C-(R \cdot \Delta R+S+F+U) .
$$

The stressor-induced change in food consumption was estimated as

$$
\Delta C=\frac{10^{\left(\log _{10}(\text { specific consumption })\right)}}{C_{\text {Control }}}
$$

where $C_{\text {Control }}$ was the $y$-intercept of the regression line for specific consumption rate which represents the response of fish in the control treatment of laboratory experiments $\left(\mathrm{g}\right.$ prey.g bass $\left.{ }^{-1} \cdot \mathrm{day}^{-1}\right)$. The change in metabolism was estimated as

$$
\Delta R=\frac{R_{\text {Control }}+\Delta \text { metabolism }}{R_{\text {Control }}}
$$

where $R_{\text {Control }}$ was the specific respiration rate of fish in the 16-day control treatment and had a mean value of $0.00248 \mathrm{~g} \mathrm{O}_{2} \cdot \mathrm{g} \mathrm{bass}^{-1}$. day $^{-1}(\mathrm{SE}=0.000192, n=4$; D.W. Beyers, unpublished data $)$.

\section{Model evaluation}

\section{Comparison of predicted and observed values}

To evaluate performance of the SRM, we used it to estimate growth of largemouth bass in dieldrin exposure studies (Beyers et al. 1999) and then compared predicted and observed values. Use of this observed data set represents a partially circular demonstration of SRM performance because the same data were used to estimate $\Delta C$ and $\Delta R$ parameters of the model. However, model evaluation using this data set has merit because the observed data are completely independent of the basic bioenergetics model component of the SRM. Thus, the observed data provide a means of evaluating (i) the performance of the basic bioenergetics model and (ii) the mechanism used to incorporate the exposure-response relationships for food consumption and metabolism into the model, but cannot be used to validate predictions of the exposure-response relationships themselves.

Predicted data for largemouth bass in the 16-day treatment were obtained by using each fish's initial mass, exposure concentration, and exposure duration in the SRM and simulating growth for the experimental period. During the experiment, fish were offered a daily ration that was less than maximum consumption. Consequently, the proportion of maximum consumption $(p)$ for each simulation was set to a value of 0.380 , which was equivalent to the percentage of $C_{\max }$ consumed by control fish. Lastly, the response of $\Delta$ metabolism for naive fish exposed to dieldrin is complex and changes over time (Beyers et al. 1999). Consequently, for these simulations the parameter for duration of exposure (DE) was updated on a daily time step to account for the influence of changing exposure duration on metabolic rate. 
Fig. 2. Predicted and observed growth rates of largemouth bass exposed to five dieldrin concentrations (control, 963, 1840, 3140, and $5790 \mathrm{ng} \cdot \mathrm{L}^{-1}$ ) for 16 days in a laboratory study. Predicted values were estimated with the SRM.

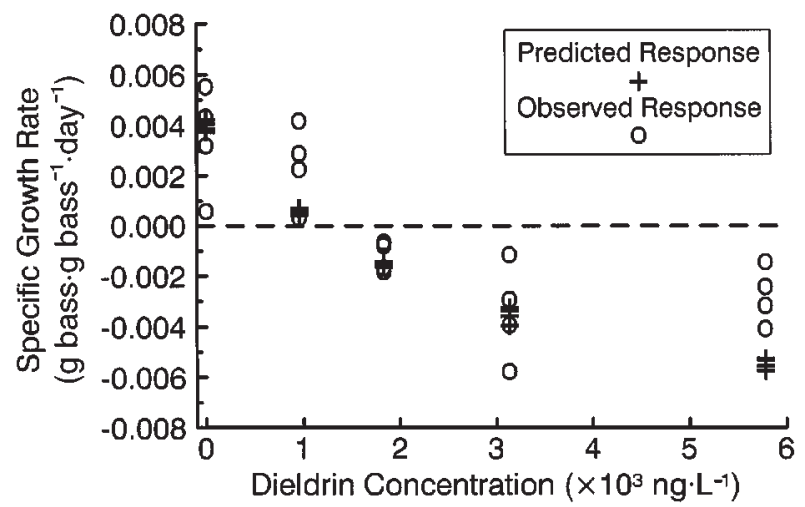

\section{Sensitivity analysis}

Sensitivity analyses (Bartell et al. 1986) were conducted to quantify the dependence of SRM predictions on model parameters. To confirm consistent methodology, we successfully replicated the analysis conducted by Bartell et al. (1986) that assessed the sensitivity of largemouth bass growth rate to variation in model parameters that do not directly determine rates of food consumption. Subsequently, three analyses of the SRM were conducted to evaluate parameter contribution to variability in predicted daily growth of a 100-g largemouth bass at $20^{\circ} \mathrm{C}$.

In the first analysis of the SRM, we omitted the parameters $\Delta C$ and $\Delta R$. Thus, the first analysis represents performance of the basic bioenergetics model and was used as a baseline for comparisons with the other SRM sensitivity analyses. The second sensitivity analysis included all SRM parameters with an environmentally relevant dieldrin concentration of $5 \mathrm{ng} \cdot \mathrm{L}^{-1}$ and duration of exposure of 16 days. Nominal values for $\Delta C$ and $\Delta R$ were calculated by solving the equations shown above after substituting for dieldrin concentration and duration of exposure. The third analysis of the SRM was identical to the second except the dieldrin concentration was $3000 \mathrm{ng} \cdot \mathrm{L}^{-1}$. This magnitude of exposure has no relevance to field conditions at the Refuge but was conducted to explore potential changes in sensitivity to parameter values at other dieldrin concentrations.

For each analysis, statistical distributions were assigned to parameters using nominal values as the means of normal distributions. Each distribution was assigned a standard deviation equivalent to $2 \%$ of its mean; thus the coefficient of variation for all distributions was $2 \%$. This magnitude of parameter variability was selected because analysis with $2 \%$ coefficient of variation is thought to give an adequate approximation to the partial derivatives in analytical sensitivity analysis (Bartell et al. 1986). Five hundred simulations were performed for each model with parameter values chosen from their distributions using Latin hypercube sampling (McKay et al. 1979; Kirchner 1995). Parameters were ranked with respect to their influence on model predictions using the method of relative partial sums of squares. Relative partial sums of squares quantifies the amount of residual variance accounted for by an individual parameter after effects of all other parameters are statistically removed. Justification and advantages of relative partial sums of squares are detailed in Bartell et al. (1986). All statistical analyses were conducted using SAS ${ }^{\circledR}$ statistical software (SAS Institute 1990).

\section{Model simulations}

Simulations were conducted with the SRM to assess the effects
Table 1. Results of Monte Carlo sensitivity analysis of the basic bioenergetics model and the SRM at two dieldrin concentrations.

\begin{tabular}{|c|c|c|c|}
\hline Parameter & $\begin{array}{l}\text { Bioenergetics } \\
\text { model }\end{array}$ & $\begin{array}{l}\text { SRM } \\
\left(5 \mathrm{ng} \cdot \mathrm{L}^{-1}\right)\end{array}$ & $\begin{array}{l}\text { SRM } \\
\left(3000 \mathrm{ng} \cdot \mathrm{L}^{-1}\right)\end{array}$ \\
\hline \multicolumn{4}{|l|}{ Food consumption } \\
\hline CA $(0.33)$ & 3 & 3 & 7 \\
\hline CB $(-0.325)$ & 2 & 2 & 4 \\
\hline CQ (2.65) & 7 & 8 & 10 \\
\hline СТO (27.5) & 1 & 1 & 1 \\
\hline CTM (37) & 10 & & \\
\hline$p(0.5)$ & 4 & 4 & 8 \\
\hline$\Delta C(0.999,0.450)$ & & 5 & 9 \\
\hline \multicolumn{4}{|l|}{ Respiration } \\
\hline RA (0.00279) & 8 & 10 & 5 \\
\hline $\mathrm{RB}(-0.355)$ & 6 & 7 & 3 \\
\hline RQ (0.0811) & 5 & 6 & 2 \\
\hline \multicolumn{4}{|l|}{ RTO (0.0196) } \\
\hline \multicolumn{4}{|l|}{ VEL (1.00) } \\
\hline SDA $(0.163)$ & 9 & & \\
\hline$\Delta R(1.00,1.03)$ & & 9 & 6 \\
\hline \multicolumn{4}{|c|}{ Egestion and excretion } \\
\hline \multicolumn{4}{|c|}{ FA $(0.104)$} \\
\hline \multicolumn{4}{|l|}{ UA $(0.068)$} \\
\hline$R^{2}$ & 0.998 & 0.998 & 0.998 \\
\hline
\end{tabular}

Note: The 10 most influential parameters for each model are ranked in order of importance, with 1 being most important. Nominal parameter values are in parentheses; parameter notation after Hewett and Johnson (1992)

of three levels of chemical exposure $\left(0\right.$, ambient, and $1000 \mathrm{ng} \cdot \mathrm{L}^{-1}$ dieldrin) on growth of largemouth bass. The ambient dieldrin concentration was $7.73 \mathrm{ng} \cdot \mathrm{L}^{-1}$ based on samples collected from Lower Derby Lake. The third SRM simulation with an exposure concentration of $1000 \mathrm{ng} \cdot \mathrm{L}^{-1}$ has no relevance to environmental conditions at the Refuge but was conducted to explore model performance over a broad range of dieldrin concentrations.

Each simulation started with a 100-g largemouth bass that fed at $50 \%$ of its maximum ration. Growth was simulated for a 160-day period starting on 9 May and ending on 16 October 1996. The thermal regime was based on water temperature data collected during that same time period from Lower Derby Lake at a depth of 2 $3 \mathrm{~m}$.

\section{Results}

\section{Model evaluation}

\section{Comparison of predicted and observed values}

Estimates of largemouth bass growth in the 16-day exposure experiment were in general agreement with observed responses (Fig. 2). Model estimates were less variable than observed data at all exposure concentrations. Predicted values fell within the ranges of observed data at dieldrin concentrations of $0-3140 \mathrm{ng} \cdot \mathrm{L}^{-1}$. Predicted growth of largemouth bass at the highest exposure concentration was slightly biased compared with observed data; however, estimated growth was only about $0.2 \% \cdot$ day $^{-1}$ less than observed. Dieldrin concentrations in lakes at the Refuge are less than $25 \mathrm{ng} \cdot \mathrm{L}^{-1}$ and fall within a concentration range where SRM predictions are in close agreement with observed data. 
Fig. 3. Simulated (A) cumulative growth and (B) daily growth rate of largemouth bass using a natural temperature regime and dieldrin exposure conditions of 0 , ambient $\left(7.73 \mathrm{ng} \cdot \mathrm{L}^{-1}\right)$, and $1000 \mathrm{ng} \cdot \mathrm{L}^{-1}$. Growth trajectories for the $0 \mathrm{ng} \cdot \mathrm{L}^{-1}$ and ambient concentrations are not discernibly different. The influence of water temperature (a natural stressor) on growth is apparent at all exposure concentrations.
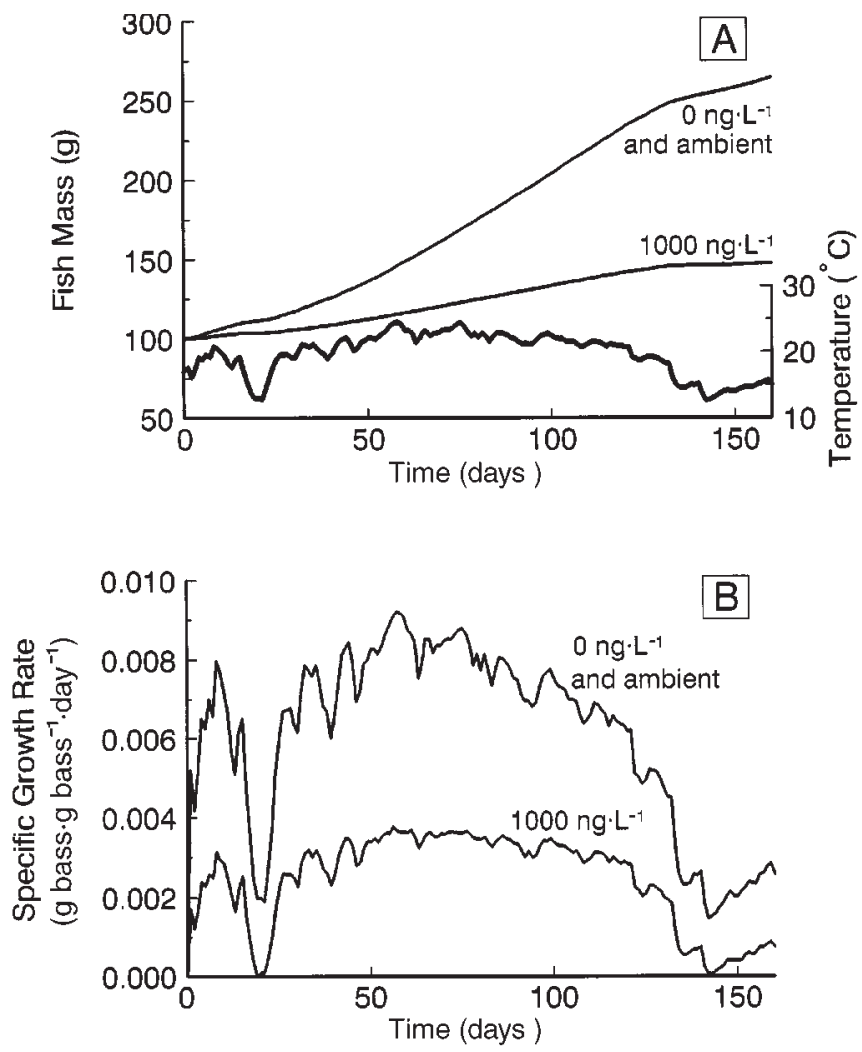

\section{Sensitivity analysis}

Analysis of the basic bioenergetics model for largemouth bass showed that the four most important parameters were related to food consumption (Table 1). This result is consistent with previous analyses; Bartell et al. (1986) described how mathematical position and magnitude of these parameters in the model contribute to their influence on growth rate. Respiration parameters were relatively less important compared with food consumption but ranked above specific dynamic action, egestion, and excretion.

The relative ranks for parameters common to the basic bioenergetics model and the SRM were unchanged at a dieldrin concentration of $5 \mathrm{ng} \cdot \mathrm{L}^{-1}$. The parameters $\Delta C$ and $\Delta R$ superseded the fifth- and ninth-ranked parameters of the basic model but did not change the order of importance. In contrast, at a dieldrin concentration of $3000 \mathrm{ng} \cdot \mathrm{L}^{-1}$, only the most influential model coefficient, the optimum temperature for food consumption, retained its relative importance. The analysis suggests that at higher levels of dieldrin exposure, contaminant-induced reduction in food consumption lessens the importance of related parameters and results in an increase in the influence of metabolism on growth rate. Despite a strong influence on rank, exposure concentration did not affect which food consumption and respiration parameters were most important. The same 10 parameters were identified by both analyses of the SRM, suggesting that future research should emphasize effects of contaminants, fish size, and temperature on food consumption and metabolic rate in order to obtain precise growth rate predictions.

\section{Model simulations}

Simulations were conducted with the SRM to assess the effects of exposure to 0 , ambient, and $1000 \mathrm{ng} \cdot \mathrm{L}^{-1}$ dieldrin. In the absence of dieldrin, a 100-g largemouth bass grew to $264 \mathrm{~g}$ by the end of a simulation (Fig. 3A). Under ambient exposure conditions of $7.73 \mathrm{ng} \cdot \mathrm{L}^{-1}$, a $100-\mathrm{g}$ fish grew to $263 \mathrm{~g}$. Thus the predicted amount of energy lost by a largemouth bass in Lower Derby Lake from chemical exposure is equivalent to about $1 \mathrm{~g}$ or $0.6 \%$ of the net growth of unexposed fish based on simulated conditions. This magnitude of effect is so small that it is not visually discernable in Fig. 3 because growth trajectories overlap. Dieldrin exposure at $1000 \mathrm{ng} \cdot \mathrm{L}^{-1}$ had a much greater effect: a 100 -g bass grew to only $148 \mathrm{~g}$, which is equivalent to about $29 \%$ of the net growth of unexposed fish. This concentration is much greater than existing levels of environmental contamination in lakes at the Refuge, but the simulation does demonstrate that the SRM performed as expected over a broad range of chemical stressor magnitudes. The simulations also demonstrate the ability of the SRM to simultaneously integrate effects of chemical and environmental stressors as revealed by the influence of water temperature on growth rate of largemouth bass (Fig. 3B). Growth rates were strongly influenced by water temperature and increased or decreased with it.

\section{Discussion}

\section{Biological significance of chemical exposure}

SRM predictions suggest that the energetic costs incurred by largemouth bass from dieldrin exposure at the Refuge are not biologically significant. Simulations showed that energy lost by a 100 -g fish during a 160 -day period is equivalent to about $1 \mathrm{~g}$ of largemouth bass flesh, which translates into $4.03 \mathrm{~g}$ of prey for a $263 \mathrm{-g}$ fish at $20^{\circ} \mathrm{C}$. This quantity of energy is negligible compared with variability in total food consumption of individual fish during a summer. In addition, this energy loss would not prevent fish from recruiting to subsequent year-classes. Consequently, characteristics of the largemouth bass population would not be altered either.

A comparison of the effect of dieldrin exposure relative to a natural stressor represents another way of evaluating biological significance. In this case, the effect of the chemical stressor was trivial compared with that of the natural stressor water temperature. Short-duration temperature fluctuations had much greater influence on fish growth than exposure to ambient dieldrin. For example, cool conditions that started on day 15 of the simulation and lasted for 9 days decreased fish growth rates, whereas the effect of chemical exposure could not be discerned even after the entire 160-day simulation (Fig. 3). This example illustrates the advantages of using a bioenergetics model to integrate natural environmental variability with laboratory-derived exposure-response relationships. By simultaneously accounting for effects of chemical and thermal stressors, the relative influence of each can be contrasted. 
Our investigation did not account for all of the ways that dieldrin may influence largemouth bass. For example, the relatively short-term, high-concentration laboratory studies that we conducted (Beyers et al. 1999) did not detect subtle changes in reproductive physiology or behavior. Contaminant-induced changes in these characteristics could have significant effects over the lifetime of a fish. In addition, our investigation did not account for dieldrin exposure from consumption of contaminated prey. Despite these limitations, conclusions of the bioenergetics analysis are consistent with findings of field investigations at the Refuge. MacRury and Johnson (1999) conducted surveys to compare growth of largemouth bass from Refuge and reference lakes in Colorado. They found that after lifetime exposure, growth rates of 3- and 4-year-old largemouth bass were faster in Lower Derby Lake than in four of five reference lakes. They also found that successful reproduction occurred annually. This evidence supports our contention that exposure to ambient dieldrin concentrations at the Refuge does not significantly affect largemouth bass and that costs of contaminantinduced stress are being compensated for.

\section{Implications for management}

Our results suggest that attempts to improve environmental conditions for largemouth bass at the Refuge by reducing dieldrin levels will not produce detectable changes in growth rates or age structure. Effects of exposure to ambient dieldrin concentrations are small compared with those of a natural stressor like water temperature. Controlling the influence of natural stressors is beyond the scope of most resource management programs. However, abundance of prey is one natural stressor (Fig. 1) that resource managers can manipulate, and it is likely that management actions aimed at increasing availability of prey will have greater benefits for largemouth bass than reducing current levels of contamination.

Sensitivity analysis of the SRM showed that the four most important parameters influencing predictions of growth rate were related to food consumption. The variation propagated by the sensitivity analysis is for assessment of the importance of parameter variability and measurement error on SRM predictions and does not reflect probabilistic behavior of the natural system (Gardner et al. 1980). However, the result that growth of largemouth bass is more strongly influenced by food consumption parameters like the realized proportion of maximum consumption $(p)$ than by the influences of contaminant exposure supports the contention that in lakes at the Refuge, management of the fish community has greater potential to improve environmental conditions for largemouth bass than remediation of contaminant concentrations.

\section{Conclusions}

The SRM provides a generally applicable framework for evaluating the biological significance of human-induced stress on animals that simultaneously experience effects of natural environmental stressors. An advantage of this approach is that it allows relative comparisons of effects of anthropogenic and natural stressors using the common currency of energy. Assessing the relative influence of each stressor can provide guidance about how to target the most sensitive components of a contaminated system to achieve the greatest benefit for a given amount of remediation effort. The SRM provides investigators and risk managers with a tool that can be used to predict the outcome of various exposure scenarios and evaluate the costs and benefits of each.

SRM simulations were intended to quantify the relative change in the bioenergetics budgets of unexposed and exposed fish under simulated environmental conditions. Beyers et al. (1999) asserted that estimating the relative change in an organism exposed to a stressor is more important than establishing whether it is within "normal limits" because norms change over time and are dependent on individual and environmental characteristics. The SRM is consistent with this approach because simulations can be run under identical conditions except for the stressor of concern and the effects of exposure can be isolated. Thus, the change in the bioenergetics budget that results from exposure serves as the basis for inferences about importance of a stressor.

The ultimate goal of investigations into effects of anthropogenic pollutants on aquatic organisms should be to understand how exposure influences the ecology of target species, not just to describe how exposure affects an organism's physiology or growth. An energetics-based approach for assessing contaminant exposure is consistent with this goal because it fosters thoughtful consideration of how stressors affect all parts of an organism's energy budget. Fish growth rates and size are inextricably linked. Fish size mediates the outcome of many ecological processes like reproduction, predation, and competition. Consequently, an energeticsbased approach can be used to quantify how physiological changes in individuals can produce effects that ripple through the population, community, and ecosystem. By integrating bioenergetics, toxicological exposure-response relationships, and natural environmental stressors using mathematical models, scientists and managers can assess significance of human-induced change at multiple levels of biological organization.

\section{Acknowledgments}

We are grateful to Catherine J. Henry for her participation in this research and for acting as the liaison with the funding source. We thank Jennifer Kleffner, Ryan Poole, and Mark Pearson for their help during the data collection phase of this research. Brett M. Johnson and Nicole MacRury provided helpful suggestions during development of the SRM. Eric Robertson contributed to the original code for the SRM. Steven M. Bartell and Robert H. Gardner graciously clarified aspects of sensitivity analysis. We are also grateful to John Roff, Alan Heath, and three anonymous reviewers for comments that improved the manuscript. This investigation was funded by the Department of the Interior, U.S. Fish and Wildlife Service, contract No. 14-16-0009-1552.

\section{References}

Adams, S.M., and Breck, J.E. 1990. Bioenergetics. In Methods for fish biology. Edited by C.B. Schreck and P.B. Moyle. American Fisheries Society, Bethesda, Md. pp. 389-415. 
Bartell, S.M., Breck, J.E., Gardner, R.H., and Brenkert, A.L. 1986. Individual parameter perturbation and error analysis of fish bioenergetics models. Can. J. Fish. Aquat. Sci. 43: 160-168.

Beyers, D.W., and Sikoski, P.J. 1994. Acetylcholinesterase inhibition in federally endangered Colorado squawfish exposed to carbaryl and malathion. Environ. Toxicol. Chem. 13: 935-939.

Beyers, D.W., Rice, J.A., Clements, W.H., and Henry, C.J. 1999. Estimating physiological cost of chemical exposure: integrating energetics and stress to quantify toxic effects in fish. Can. J. Fish. Aquat. Sci. 56. This issue.

Brandt, S.B., and Hartman, K.J. 1993. Innovative approaches with bioenergetics models. Trans. Am. Fish. Soc. 122: 731-1030.

Brett, J.R., and Groves, T.D.D. 1979. Physiological energetics. In Fish physiology. Vol. 8. Edited by W.S. Hoar, D.J. Randall, and J.R. Brett. Academic Press, New York. pp. 279-352.

Elliot, J.M., and Davidson, W. 1975. Energy equivalents of oxygen consumption in animal energetics. Oecologia, 19: 195-201.

Gardner, R.H., Huff, D.D., O’Neill, R.V., Mankin, J.B., Carney, J., and Jones, J. 1980. Application of error analysis to a marsh hydrology model. Water Resour. Res. 16: 659-664.

Hanson, P.C., Johnson, T.B., Schindler, D.E., and Kitchell, J.F. 1997. Fish bioenergetics 3.0. Tech. Rep. Univ. Wis. Sea Grant Inst. No. WISCU-T-97-001.

Helsel, D.R. 1990. Less than obvious: statistical treatment of data below the detection limit. Environ. Sci. Technol. 24: 17661774.

Hewett, S.W., and Johnson, B.L. 1992. Fish bioenergetics model 2. Tech. Rep. Univ. Wis. Sea Grant Inst. No. WIS-SG-92-250.
Kirchner, T.B. 1995. TIME-ZERO: the integrated modeling environment reference manual. Quaternary Software, Fort Collins, Co.

Kitchell, J.F. 1983. Energetics. In Fish biomechanics. Edited by P.W. Webb and D. Weihs. Praeger, New York. pp. 312-338.

MacRury, N.K. and B.M. Johnson. 1999. Sublethal responses of largemouth bass to parasites and organochlorines. Environ. Toxicol. Chem. 18: 998-1006.

McKay, M.D., Beckman, R.J., and Conover, W.J. 1979. A comparison of three methods for selecting values of input variables in the analysis of output from a computer code. Technometrics, 21: 239-245.

Newman, M.C., Greene, K.D., and Dixon, P.M. 1995. UnCensor ${ }^{\odot}$, version 4.0. Savannah River Ecology Laboratory, Aiken, S.C.

Rice, J.A. 1990. Bioenergetics modeling approaches to evaluation of stress in fishes. Am. Fish. Soc. Symp. 8: 80-92.

Rice, J.A., Breck, J.E., Bartell, S.M., and Kitchell, J.F. 1983. Evaluating the constraints of temperature, activity and consumption on growth of largemouth bass. Environ. Biol. Fishes, 9: 263275.

SAS Institute. 1990. SAS/STAT users guide, version 6, edition 4. Vol. 2. SAS Institute Inc., Cary, N.C.

Selye, H. 1956. The stress of life. McGraw-Hill Book Company, New York.

Selye, H. 1973. The evolution of the stress concept. Am. Sci. 61: 692-699.

Warren, C.E. 1971. Biology and water pollution control. W.B. Saunders Company, Philadelphia, Pa. 